\title{
Can ion mobility-mass spectrometry and density functional theory help elucidate protonation sites in 'small' molecules?
}

\author{
Cris Lapthorn ${ }^{1}$, Trevor J. Dines ${ }^{2}$, Babur Z. Chowdhry ${ }^{1}$, George L Perkins ${ }^{3}$, \\ Frank Pullen ${ }^{1 *}$
}

${ }^{1}$ School of Science, University of Greenwich, Medway Campus, Chatham, Kent ME4 4TB, UK

${ }^{2}$ Division of Physics, University of Dundee, Dundee DD1 4HN, UK

${ }^{3}$ PerkinElmer Inc, 29 Business Park Drive, Branford CT 06405, USA.

\begin{abstract}
ACCEPTED FOR PUBLICATION
This is the peer reviewed version of the following article:

Lapthorn, C., Dines, T. J., Chowdhry, B. Z., Perkins, G. L. and Pullen, F. S. (2013), Can ion mobility mass spectrometry and density functional theory help elucidate protonation sites in 'small' molecules?. Rapid Commun. Mass Spectrom., 27: 2399-2410. doi: 10.1002/rcm.6700 which has been published in final form at http://dx.doi.org/10.1002/rcm.6700 This article may be used for non-commercial purposes in accordance with Wiley Terms and Conditions for self-archiving. http://olabout.wiley.com/WileyCDA/Section/id-817011.html
\end{abstract}

RATIONALE: Ion mobility spectrometry-mass spectrometry (IMS-MS) offers an opportunity to combine measurements and/or calculations of the collision cross-sections and subsequent mass spectra with computational modelling in order to derive the threedimensional structure of ions. IMS-MS has previously been reported to separate two components for the compound norfloxacin, explained by protonation on two different protonation sites enabling the separation of protonated isomers (protomers) using ion mobility with distinguishable MS/MS data. This study reveals further insights into the specific example of norfloxacin and wider implications for ion mobility mass spectrometry.

METHODS: Using a Waters Synapt G2 quadrupole-ion mobility-time of flight mass spectrometer the IMS and MS/MS spectra of norfloxacin were recorded and compared with theoretical calculations using molecular modelling (density functional theory), and subsequent collision cross section calculations using projection approximation.

RESULTS: A third significant component in the ion mobilogram of norfloxacin was observed under similar experimental conditions to those previously reported. The presence of the new component is convoluted by co-elution with another previously observed component. CONCLUSIONS: This case demonstrates the potential of combined IMS-MS/MS with molecular modelling information for increased understanding of 'small-molecule' fragmentation pathways.

* Correspondence to: F. Pullen, School of Science, University of Greenwich, Medway Campus, Chatham Maritime, Kent ME4 4TB, UK.

E-mail: frank.pullen@gre.ac.uk 
The fragmentation of the protonated molecule forms the basis of most structural studies using electrospray mass spectrometry. The existence of isomers differing by protonation site (protomers) and/or tautomeric state, can be important in interpretation of both ion mobility and mass spectrometry data. The protonation site can have a profound effect on the threedimensional structure of an ion and subsequent fragmentation that determines the product spectrum observed. The prevalence of protomers in 'small molecule' chemical space is difficult to accurately quantify, at the time of writing the ZINC database of commercially available compounds for virtual screening ${ }^{[1]}$ contains data on 77,242,420 substances and 0.65 protomers per substance, whereas the 2000 version of MDL Drug Data Report (MDDR) database $^{[2]}$ of biologically relevant compounds contained data on 106,592 structures and 6.83 protomers per compound.

Using mass spectrometry alone it can be difficult to infer which site is protonated in the gas phase and many recent studies aim to build general rules and methodologies to predict fragmentation. The use of ion mobility mass spectrometry to study the effect of protonation has been previously reported for norfloxacin. ${ }^{[3]}$ In the aforementioned study the ion mobility stage was used to separate ions according to their ion mobilities; presumably with different protonation sites having slightly different ion mobilities. The resulting MS-MS spectra appear consistent with this explanation (Scheme 1; Fig. 1) as two peaks are observed in the ion mobilogram and changing the cone voltage from between 10, 120 and 200V changes the appearance of the mass spectrum, consistent with the proposed fragmentation pathway. 


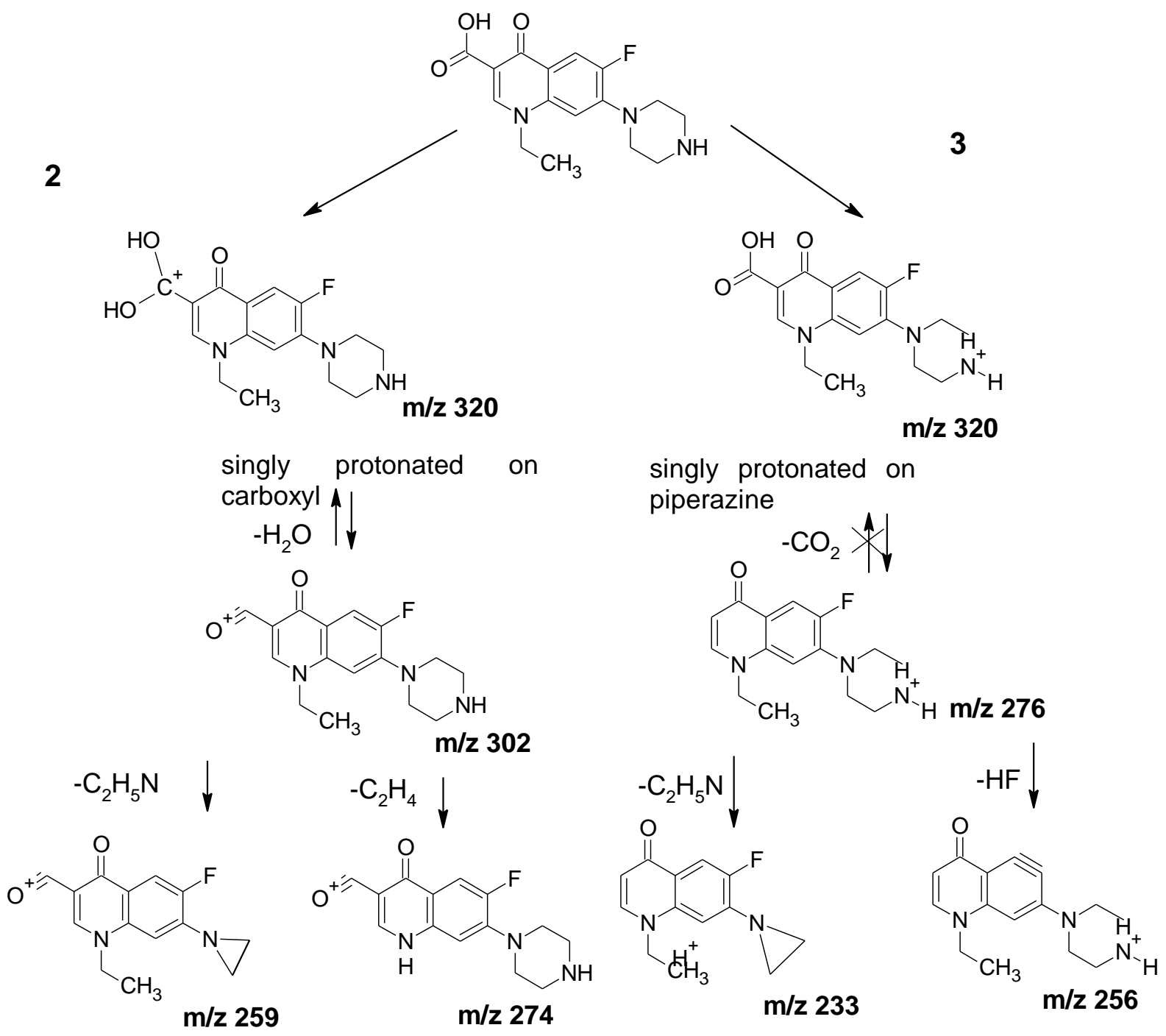

Scheme 1. Proposed fragmentation pathway for protonated norfloxacin, adapted from Kaufmann et al. ${ }^{[3]}$ 


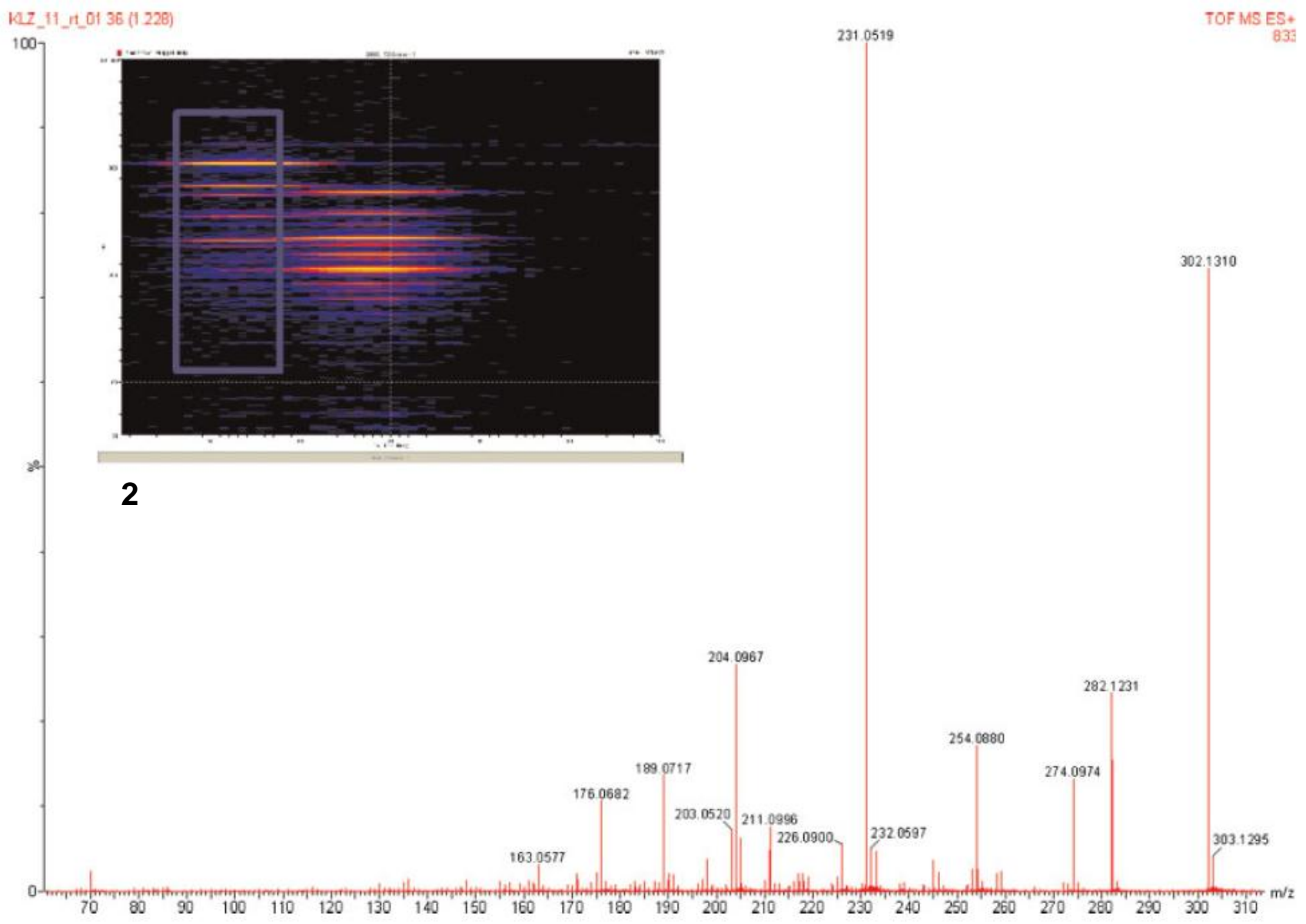






\section{2}

3
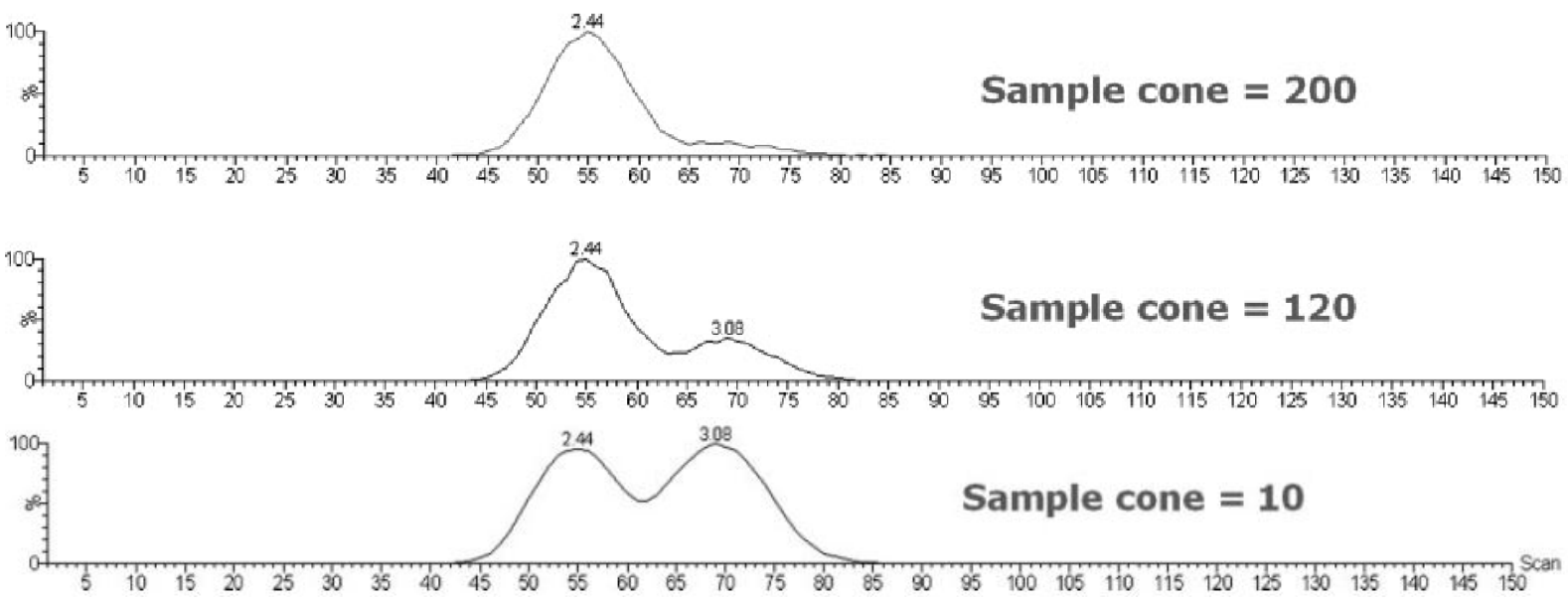

Figure 1. Ion mobility selected mass spectra and effect of sample cone voltages on arrival time distributions, adapted from Kaufmann et al. ${ }^{[3]}$.

\section{Understanding the site of protonation}

Quinolones that are structurally similar to norfloxacin are known to exist as zwitterions in neutral solutions. ${ }^{[4]}$ However, gas-phase proton transfer reactions can occur when a molecule with a high gas-phase proton affinity abstracts a proton from the protonated form of a molecule that has a lower gas-phase proton affinity. Thus an inversion in the order of basicity among a series of molecules proceeding from the solution phase to the gas phase ${ }^{[5]}$ can take 
place because solution-phase basicity (pKa) and gas-phase proton affinity are not necessarily related. This may be further complicated with different solvent composition, $\mathrm{pH}$ etc, indeed the site of protonation in norfloxacin has been proposed to be determined by the $\mathrm{pH}$, aqueousorganic ratio or ionic strength of the mobile phase used in liquid chromatography-mass spectrometry studies. ${ }^{[6]}$

The following sections highlight the important and characteristic losses from norfloxacin, which in turn enable more confident assignment of fragmentation pathways and protonation sites.

\section{Loss of $\mathrm{H}_{2} \mathrm{O}$ from norfloxacin, $m / z 320$}

The protonated ions of the three compounds in Figure 2 with carboxyl groups undergo rapid loss of $\mathrm{H}_{2} \mathrm{O}$, and subsequent loss of $\mathrm{CO}$ or other species, but no detectable loss of $\mathrm{CO}_{2}{ }^{[5]}$<smiles>CC1CCc2cc(F)cc3c(=O)c(C(=O)O)cn1c23</smiles>

flunequire<smiles>CCn1cc(C(=O)O)c(=O)c2ccc(C)nc21</smiles>

nelidxicacid<smiles>O=C(O)c1c[nH]c2cc(C(F)(F)F)ccc2c1=O</smiles>

4Hydory-7tiflicorathy3quindirecarboxylicadid

Figure 2. Three compounds related to norfloxacin lacking the piperazine ring.

It is not clear whether loss of $\mathrm{H}_{2} \mathrm{O}$ occurs only when the proton is attached to the carboxyl group during the electrospray process, or whether it is possible for a proton attached to the oxygen or nitrogen of the quinolone ring to be collisionally activated and transferred to the carboxyl group. ${ }^{[7]}$

Addition of $\mathrm{H}_{2} \mathrm{O}$ to [norfloxacin $\left.+\mathrm{H}-\mathrm{H}_{2} \mathrm{O}\right]^{+}, \mathrm{m} / z, 302$

According to Neta et al. ${ }^{[7]}$ when norfloxacin was dissolved in methanol ${ }^{[5]}$ in the absence of water, MSMSMS experiments on the $\left[\mathrm{M}+\mathrm{H}^{+}-\mathrm{H}_{2} \mathrm{O}\right]^{+}$ion $\left(\mathrm{m} / z\right.$ 302) showed addition of $\mathrm{H}_{2} \mathrm{O}$ (to form $m / z, 320$ ) as well as addition of $\mathrm{CH}_{3} \mathrm{OH}$ (to form $\mathrm{m} / z$ 334). Loss of $\mathrm{H}_{2} \mathrm{O}$ from $\mathrm{m} / z, 320$ was postulated to lead to formation of an acyl species, which has high affinity for water or alcohols. This process is most pronounced at the lowest collision energies while at higher energies the $[\mathrm{M}+\mathrm{H}]^{+}$ion undergoes fragmentation. Addition of a water molecule in the collision cell was reported for other compounds and was explained by the presence of water in the collision cell which is difficult to remove by standard pumping. ${ }^{[7]}$ This process can, reportedly, take place in the collision cell as well as in the cone region (in-source) of the spectrometer ${ }^{[8]}$ although the addition may be to form a water adduct rather than reversible fragmentation. ${ }^{[9]}$

\section{Loss of $\mathrm{CO}_{2}$ from norfloxacin, $m / z 320$}

The results reported by Neta et al. ${ }^{[7]}$ indicate that $\mathrm{m} / \mathrm{z} 320$ undergoes loss of $\mathrm{CO}_{2}$ when a positive charge or a proton is on the piperazine ring, an irreversible process based on their experimental data. 
Addition of $\mathrm{CO}_{2}$ to [norfloxacin $\left.+\mathrm{H}-\mathrm{CO}_{2}\right]^{+}, m / z 276$

Loss of $\mathrm{CO}_{2}$ leads to replacement of the $\mathrm{CO}_{2} \mathrm{H}$ group with $\mathrm{H}$, forming a relatively stable species, where addition of $\mathrm{CO}_{2}$ appears unlikely. The relative intensities of the $-\mathrm{CO}_{2}$ and $-\mathrm{H}_{2} \mathrm{O}$ product ions are believed to change with cone voltage because their rate of formation and fragmentation are likely to be different ${ }^{[7]}$.

To further understand the fragmentation of norfloxacin we carried out further experimental studies and theoretical calculation and ultimately describe another feature present in the ion mobilogram that appears consistent with an additional third structure of gas-phase norfloxacin.

\section{EXPERIMENTAL}

\section{Chemicals and materials}

Norfloxacin, poly(DL-alanine), sodium hydroxide, isopropanol and methanol were purchased from Sigma-Aldrich (Gillingham, UK), acetonitrile from Rathburn (Walkerburn, UK) and high purity water from VWR International Ltd (West Chester, USA). Formic acid was supplied by Biosolve (Valkenswaard, Netherlands).

\section{Mass spectrometry and liquid chromatography conditions}

A solution of $0.1 \mathrm{mg} / \mathrm{mL}$ of norfloxacin was prepared in methanol and $2 \mathrm{uL}$ of the $0.1 \mathrm{mg} / \mathrm{mL}$ solution was injected on to a Waters (Manchester, UK) Acquity reverse phase chromatography system using an ACQUITY UPLC® BEH C18 column (particle size:1.7 $\mu \mathrm{m})$ in a mobile phase reverse phase gradient composition of $\mathrm{A}$ : water $+0.1 \%(\mathrm{v} / \mathrm{v})$ formic acid and $\mathrm{B}$ : acetonitrile $+0.1 \%(\mathrm{v} / \mathrm{v})$ formic acid. The flow rate was $0.5 \mathrm{~mL} / \mathrm{min}$ to the electrospray source. The gradient conditions were an initial composition of $95.0 \% \mathrm{~A}$, from 0.5 mins to 4.5 mins a gradient from $95 \%$ to $40 \% \mathrm{~A}, 5 \% \mathrm{~A}$ at $4.6 \mathrm{mins}$ to $5.4 \mathrm{mins}$ and a reequilibration of $95 \%$ A from 5.5 mins to 7 mins. No splitter was used, so the entire flow was introduced to the electrospray source and the UPLC column temperature was maintained at $30^{\circ} \mathrm{C}$ throughout the run.

Experiments were performed on a Waters (Manchester, UK) Synapt G2 HDMS system with a hybrid quadrupole/traveling wave ion mobility/orthogonal acceleration time-of-flight configuration. Experiments were conducted using an electrospray ionization (ESI) source operated in the positive ion mode with a capillary voltage of $3.2 \mathrm{kV}$ and cone voltage of 30 V. An orthogonal LockSpray ${ }^{\mathrm{TM}}$ ESI probe was used with a lock mass calibrant, leucine-enkephaline, whose $[\mathrm{M}+\mathrm{H}]^{+}$ion at $\mathrm{m} / z .556 .2771$ was used as the internal mass correction calibrant. The TOF analyzer was operated in resolution mode (a resolution of 18000 at $\mathrm{m} / \mathrm{z}$ 556), acquiring 2 scans per second. The source temperature was $150^{\circ} \mathrm{C}$, desolvation temperature was $500{ }^{\circ} \mathrm{C}$, cone gas flow rate of $80 \mathrm{~L} / \mathrm{h}$ and desolvation gas flow rate of $1200 \mathrm{~L} / \mathrm{h}$. A mass calibration solution of sodium formate was prepared by mixing 0.05 $\mathrm{mM}$ sodium hydroxide solution with $0.05 \%$ formic acid in isopropanol/water $(90 / 10$; v/v) and infused at $10 \mathrm{uL} / \mathrm{min}$.

\section{Ion mobility conditions}


The collision energy in the trap and transfer ion guide was set at $6 \mathrm{eV}$, and $0 \mathrm{eV}$, respectively. The mobility $\mathrm{T}$-wave cell was operated at a pressure of $2.8 \mathrm{mbar}$ of nitrogen. The wave velocity was $600 \mathrm{~m} / \mathrm{s}$, and the wave height was fixed at $40 \mathrm{~V}$, except where stated otherwise.

\section{Data processing}

Data acquisition and processing were carried out using Masslynx 4.1 and Driftscope 2.4 (Waters Ltd, Manchester, UK) software. The $\mathrm{m} / \mathrm{z}$ range for the peak of interest was selected and Driftscope software was used to determine the collision cross-section (CCS) values of the analyte compounds by projecting their drift times onto a calibration curve. The T-wave instrument was calibrated using a well-established protocol ${ }^{[10]}$ by plotting the drift time/crosssection function (Figure 3) following data acquisition of a $10 \mathrm{mM}$ poly(DL-alanine) solution in methanol/water (50:50; v/v) under exactly the same ion mobility and mass spectrometric conditions as those used for the following analysis. The measured drift times of the poly(DLalanine) clusters were plotted against the CCSs determined on a standard IMS drift tube instrument. $^{[11]}$



Figure 3. Traveling-wave ion mobility calibration curve of a typical drift-time versus adjusted collision cross-section of a series of poly(DL-alanine)clusters. A power curve of the form $y=a x^{b}$ is fitted to the data.

\section{Density functional theory (DFT) calculations}

DFT calculations of the structures, and associated energies, of norfloxacin and its protonated derivatives were carried out with the Gaussian 09 program $^{[12]}$ (using the hybrid SCF-DFT method B3LYP, which incorporates Becke's three parameter hybrid functional ${ }^{[13]}$ and the Lee, Yang and Parr correlation functional. ${ }^{[14]}$ All calculations were performed using the 6$311++G(d, p)$ basis set, which was considered to be large enough to provide reliable relative energies. The initial model for the geometry optimisation of norfloxacin was obtained from the most recent crystal structure. ${ }^{[15]}$ Initial models for each of the protonated derivatives were constructed by placing a hydrogen atom at a distance of $1 \AA$ from each putative protonation site, followed by geometry optimisation. In the case of protonation at the carboxyl oxygen atom geometry optimisation resulted in transfer of the proton to the carbonyl oxygen atom; this representing an energetically more favourable structure, at least at this level of theory.

\section{RESULTS AND DISCUSSION}

\section{Effect of conformation and protonation site on product ion spectra}

It may be expected that the thermodynamically most favourable product ion would be generated, however it is feasible that the protonation site may be sterically hindered and thus protonation is kinetically determined. ${ }^{[16]}$ 
The conformation of ions has been demonstrated to be of importance in peptide and small molecule fragmentation patterns due to proton shifts that enable fragmentation pathways to be accessible. The effect of protonation to on CID fragmentation pathways has been previously reported for species including even electron disassociations in 4 -azasteroids, ${ }^{[15]}$ voriconazole and fluconazole, ${ }^{[68]}$ and in odd-electron disassociations in $N, N^{\prime}$ dibenzylpiperazines and $N$-benzylpiperazines ${ }^{[19]}$. For example, where a fluconazole ion is protonated on one of the three possible basic sites ${ }^{[18]}$ the hydrogen at the charge site and the hydroxyl oxygen are spatially arranged to accommodate the formation of a hydrogen bond; these two atoms being $1.787 \AA$ apart, as predicted by DFT calculations. The resulting loss of $\mathrm{H}_{2} \mathrm{O}$ (comprised of the hydroxyl and the charge hydrogen, Figure 4) results in the production of a tertiary carbocation product ion, which is indeed observed in the product ion spectrum using electrospray.

(a)

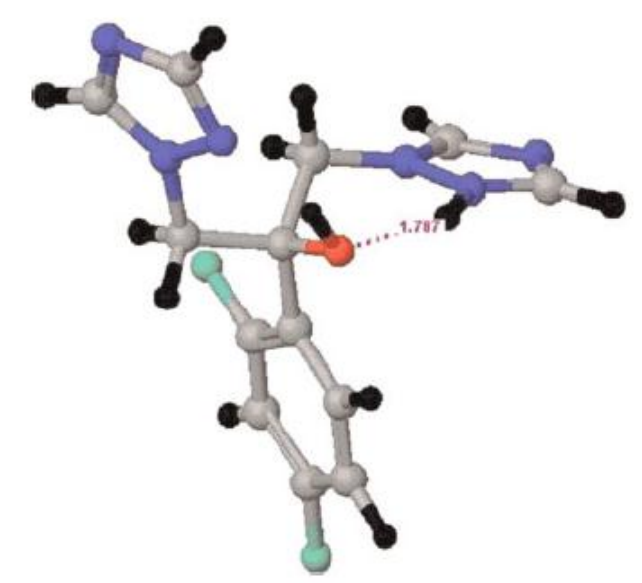

(b)

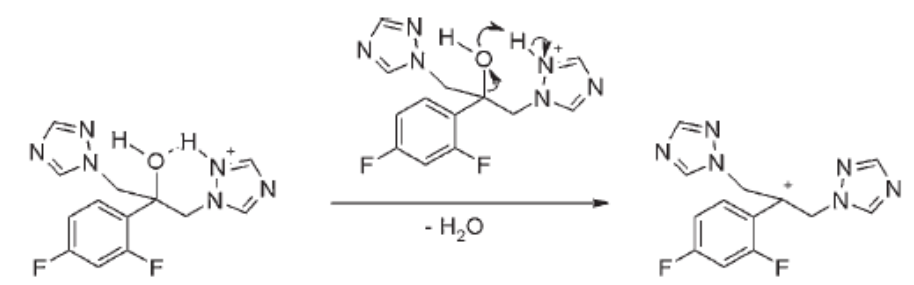

(c)

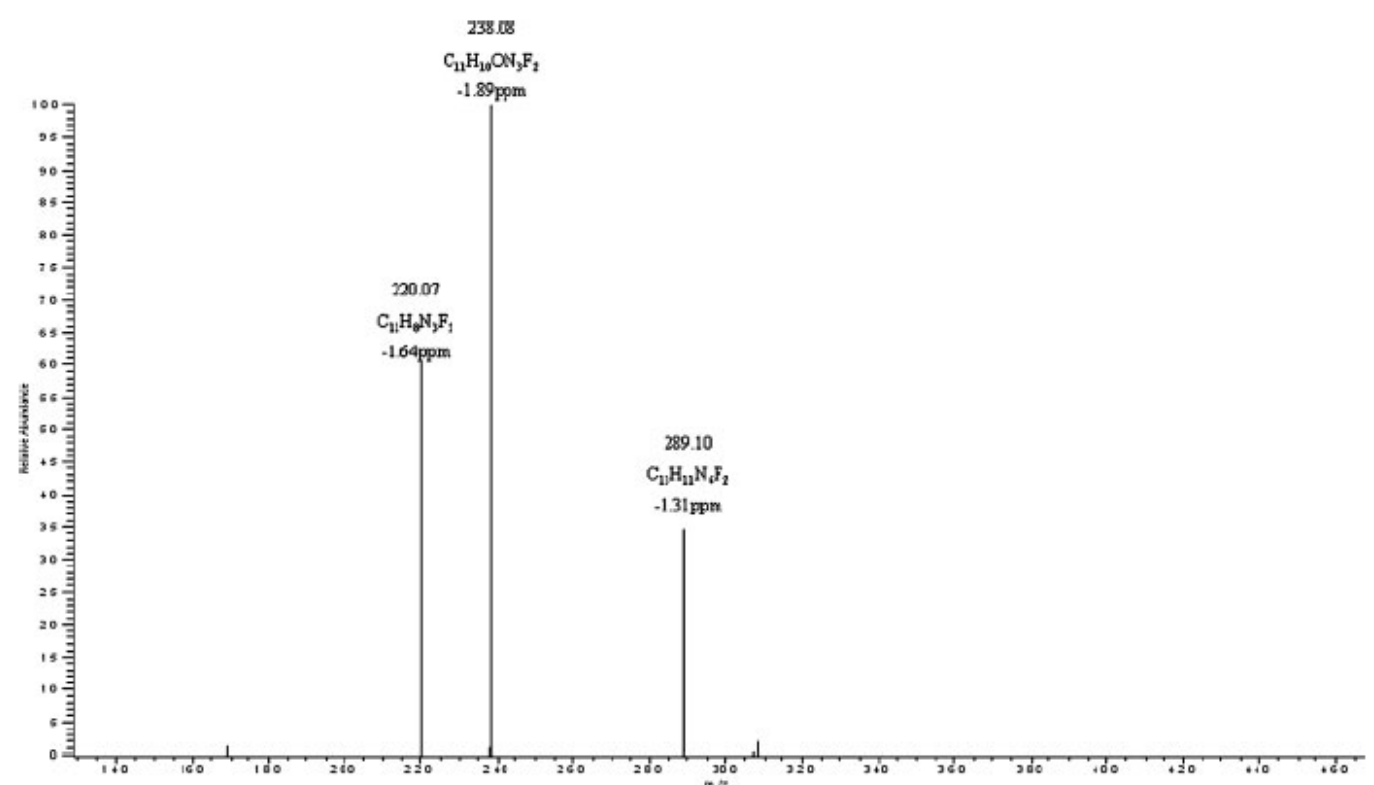

Figure 4. (a) Structure of protonated fluconazole illustrating newly formed hydrogen bond, (b) Proposed reaction mechanism that enables elimination of $\mathrm{H}_{2} \mathrm{O}$ via the formation of the hydrogen bond from the precursor at $\mathrm{m} / \mathrm{z} 307$ to $\mathrm{m} / \mathrm{z} 289$, (c) mass spectrum of fluconazole showing $[\mathrm{M}+\mathrm{H}]^{+} \mathrm{m} / \mathrm{z}, 307$ and $\left[\mathrm{M}-\mathrm{H}_{2} \mathrm{O}\right]^{+} \mathrm{m} / \mathrm{z}, 289$; adapted from Alex et al. ${ }^{(2010) 8]}$. 
In another example, the conformation of the rigid isomer pair cis and trans 3-pinanones affords a significant difference in the isobutane CI mass spectrum (Figure 5) of the cis isomer which is dominated by the loss of $\mathrm{H}_{2} \mathrm{O}$, whereas the loss of $\mathrm{C}_{2} \mathrm{H}_{4} \mathrm{O}$ is dominant in the trans isomer. ${ }^{[20]}$ The loss of $\mathrm{C}_{2} \mathrm{H}_{4} \mathrm{O}$ is supported by analysis of the spectra obtained for the 2,4,4deuterated compound which loses $\mathrm{C}_{2} \mathrm{HD}_{3} \mathrm{O}$. They proposed that protonation, by isobutane $\mathrm{CI}$, did not disturb the ground-state conformation of the isomers.

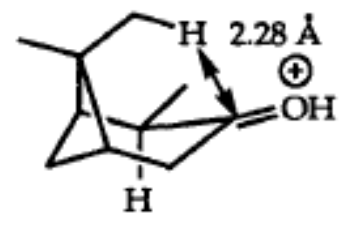

1 (cis)

$133.41 \mathrm{kcal} / \mathrm{mol}$

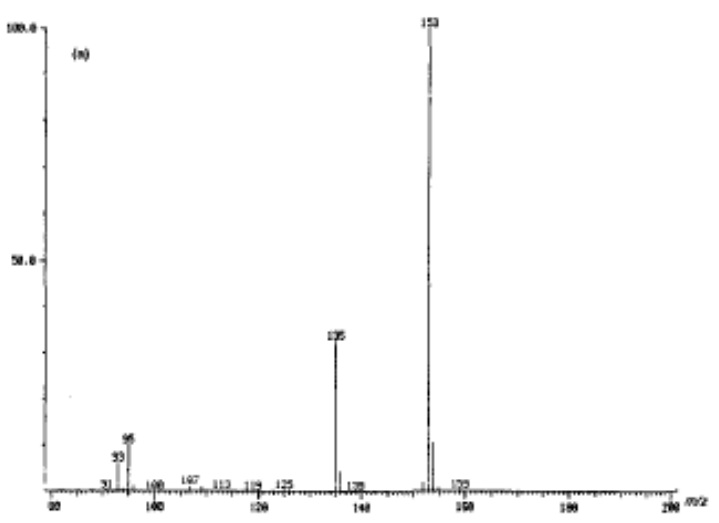

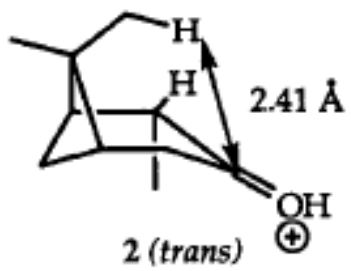

$132.84 \mathrm{kcal} / \mathrm{mol}$



Energy of hypothetical transition state (AM1)

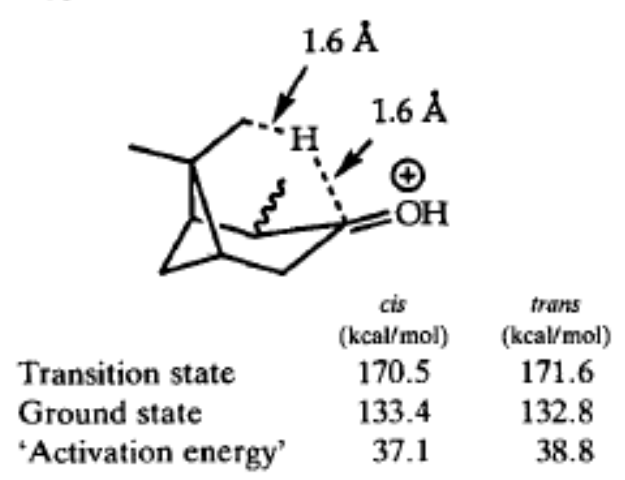

Conclusion: High activation energy for trans isomer.

Figure 5. Structure and mass spectrum for cis and trans 3-pinanone and the hypothetical transition state showing key bond lengths, adapted from Youssefi et al. ${ }^{[20]}$.

The conformation of the ions involved in fragmentation pathways have been calculated for 3pinanones using AM1 quantum chemical methods, ${ }^{[20]}$ for protonated Voriconazole ${ }^{[18]}$ measured for ephedrine using high and low resolution UV spectroscopy ${ }^{921]}$ and compared to NMR assignment for $p$-benzoquinone and 1,1-bicycloalkenyls ${ }^{[22]}$. Thus there are important relationships proposed between conformers and the subsequent accessible fragmentation pathways. 


\section{Observation of multiple components in the ion mobilogram of norfloxacin}

In contrast to the two components that have been previously reported in ion mobilograms of norfloxacin, our data shows three components when $\mathrm{m} / \mathrm{z} 320$ was selected as the precursor ion in an MS/MS experiment.

The ion mobility data was selected by retention time at $1.7 \mathrm{mins}$, initially to ensure that components from other retention times were not included in the analysis; this can be seen in the top trace in Figure 6 which shows a single peak, there are no significant peaks either side of the main peak at 1.7 mins.

Figure 6. Mass chromatogram (top trace) and ion mobilogram (bottom trace)

The ion mobilogram (shown in the bottom trace in Figure 6) initially appears to show two major peaks. However, selecting a number of arbitrary IMS bins over the left hand side of the first peak (from 53 to 55 bins inclusive) or the right hand side of the first peak (from 57 to 59 bins inclusive) results in two discernibly different mass spectra. This selection was achieved with the processing program Driftscope (Waters, Manchester UK) that allows users to select by drift-time and/or retention time.

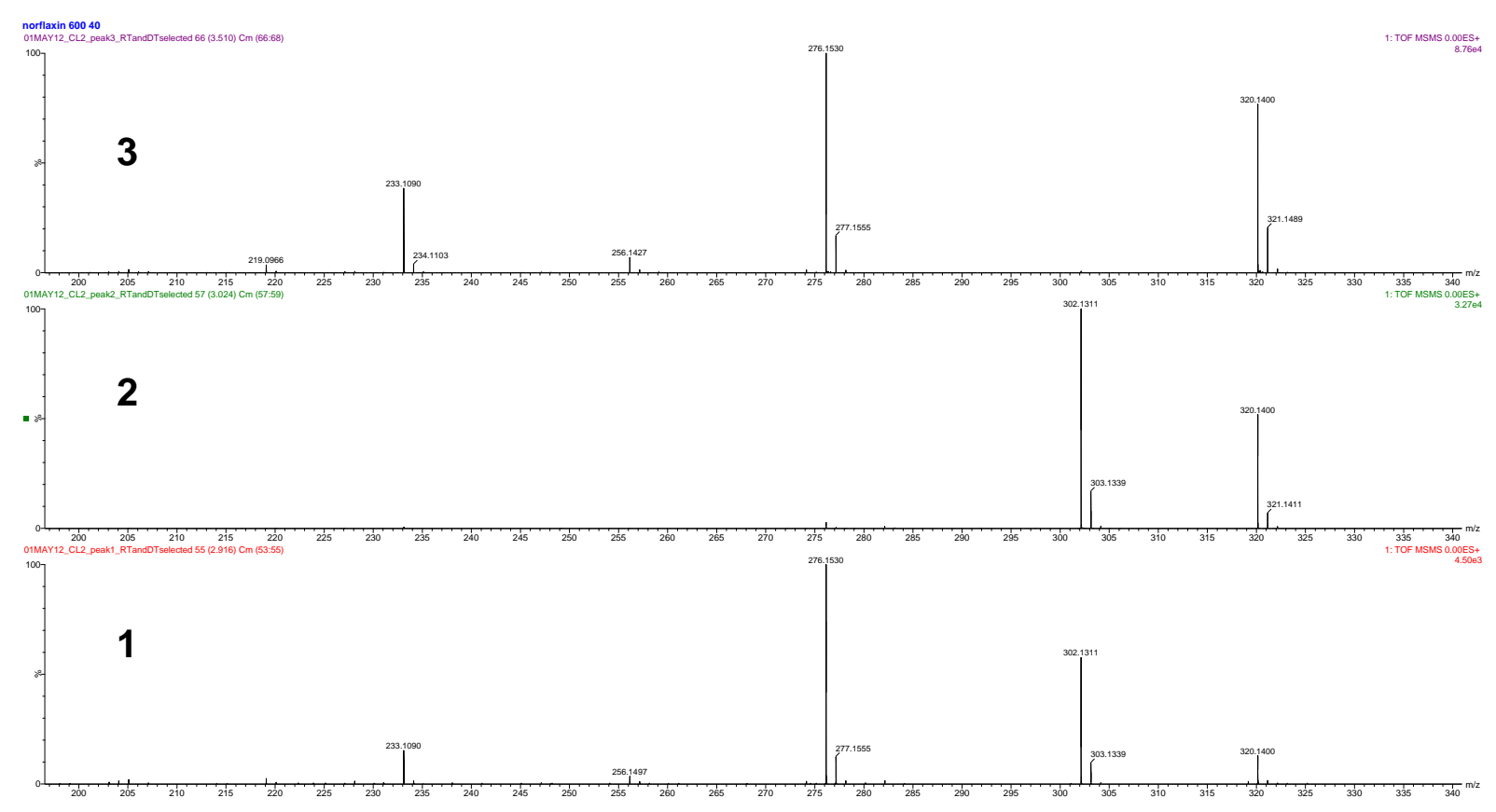

Figure 7. Mass spectra for all components observed in norfloxacin, processed from the drifttime selected mobilograms.

Interestingly component 1 , which has not been described before, appears similar to a theoretical mixture of component 2 and component 3. The presence of ion $\mathrm{m} / \mathrm{z} 302$ in the mass spectrum of component 3 indicates a loss of $\mathrm{H}_{2} \mathrm{O}$ from precursor $\mathrm{m} / \mathrm{z} 320$ (similar to component 2), however the presence of $\mathrm{m} / \mathrm{z} 276$ and $\mathrm{m} / \mathrm{z} 256$ indicates a loss of $\mathrm{CO}_{2}$ and $\mathrm{HF}$ (similar to component 3 ). 
To further understand the composition of this mixture of components in the drift-time dimension, extracted ion chromatograms are shown in Figure 8, which show the abundance of the $m / z, 302$ ion and the $m / z 276$ ion.

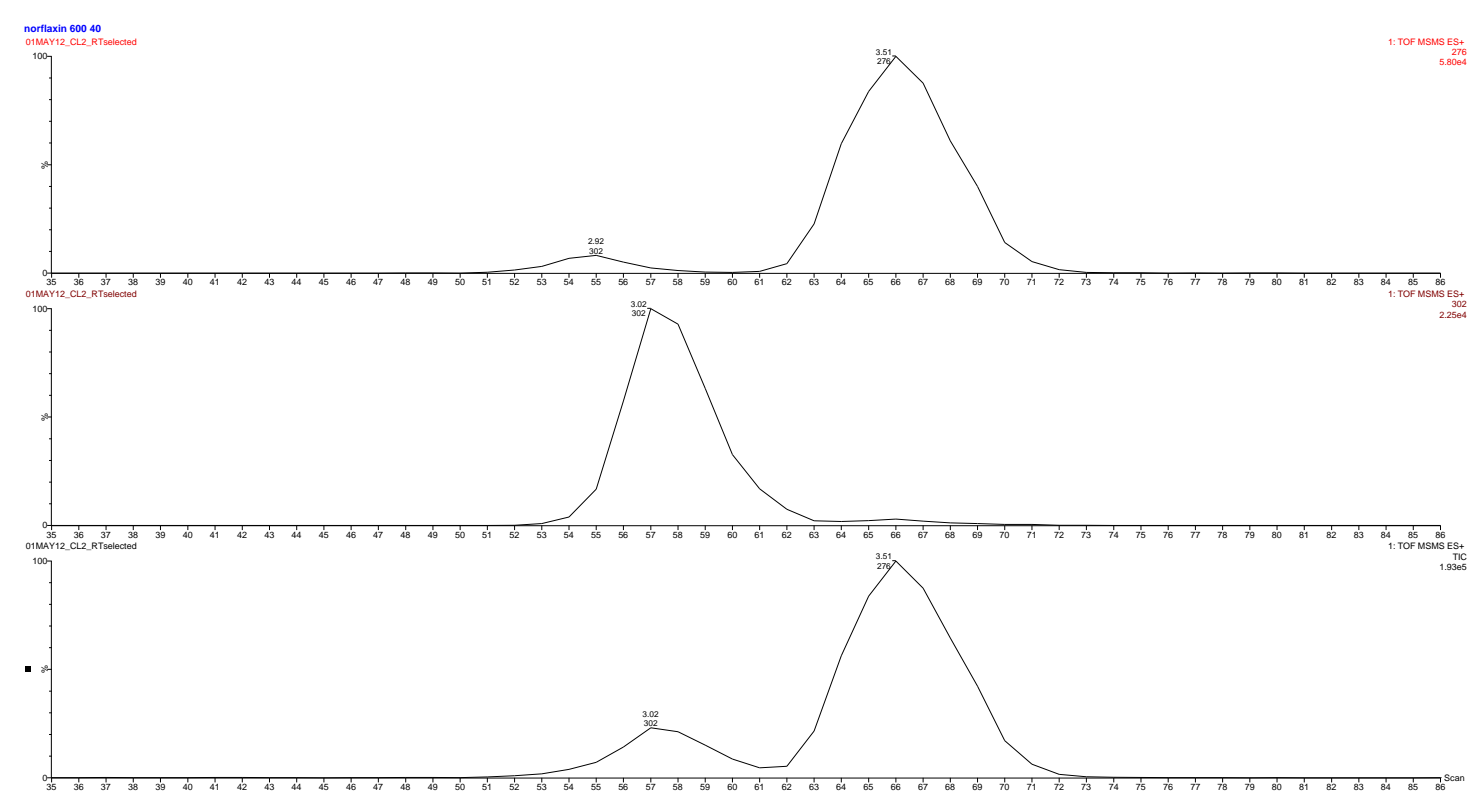

Figure 8. Bottom trace shows ion mobilogram for retention time 1.55 to 1.80 , middle trace shows extracted ion mobilogram for $\mathrm{m} / \mathrm{z} 302$, top trace shows extracted ion mobilogram for $m / z 276$

To understand the composition of the mixture further, the ion mobility measurements were repeated at $1400 \mathrm{~m} / \mathrm{s}$ wave velocity and $40 \mathrm{~V}$ wave height (Figure 9). There appear to be three components, with component 1 observed from bin 118 to 128, component 2 observed from bin 128 to 143 and component 3 observed from 143 to bin 170. The bin is an arbitrary unit to capture the drift time dimension using the Waters Synapt G2 instrument. It is interesting to note that there appears to be not only better separation of the proposed components but also the peakshape of component 3 suggests a potential fourth conformation.

To understand the composition of the mixture further, the ion mobility measurements were repeated at $1400 \mathrm{~m} / \mathrm{z}$ wave velocity and $40 \mathrm{~V}$ wave height (Fig. 9). There appear to be three components, with component 1 observed from bin 118 to 128 , component 2 observed from bin 128 to 143 and component 3 observed from 143 to bin 170 . The bin is an arbitrary unit to capture the drift time dimension using the Waters Synapt G2 instrument. It is interesting to note that there appears to be not only better separation of the components but also some fine structure in the last component peak (component 3). 


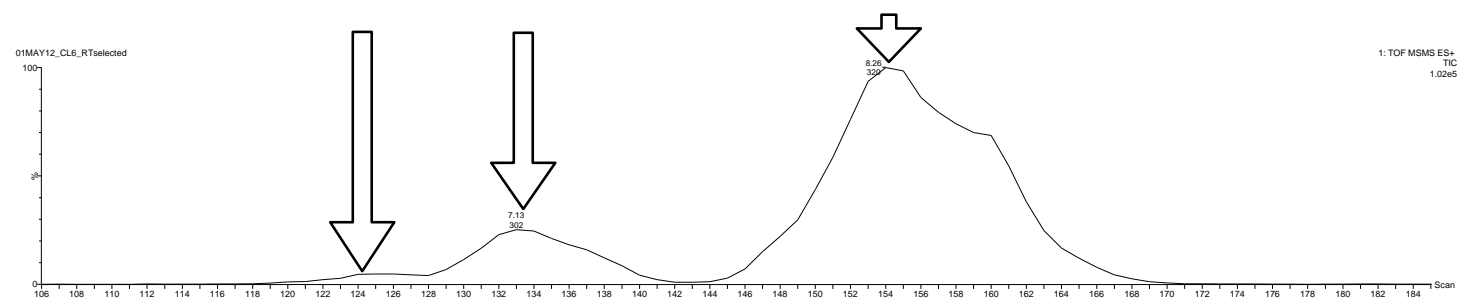

Figure 9. Ion mobilogram showing three main components and atypical peakshape in component 3.

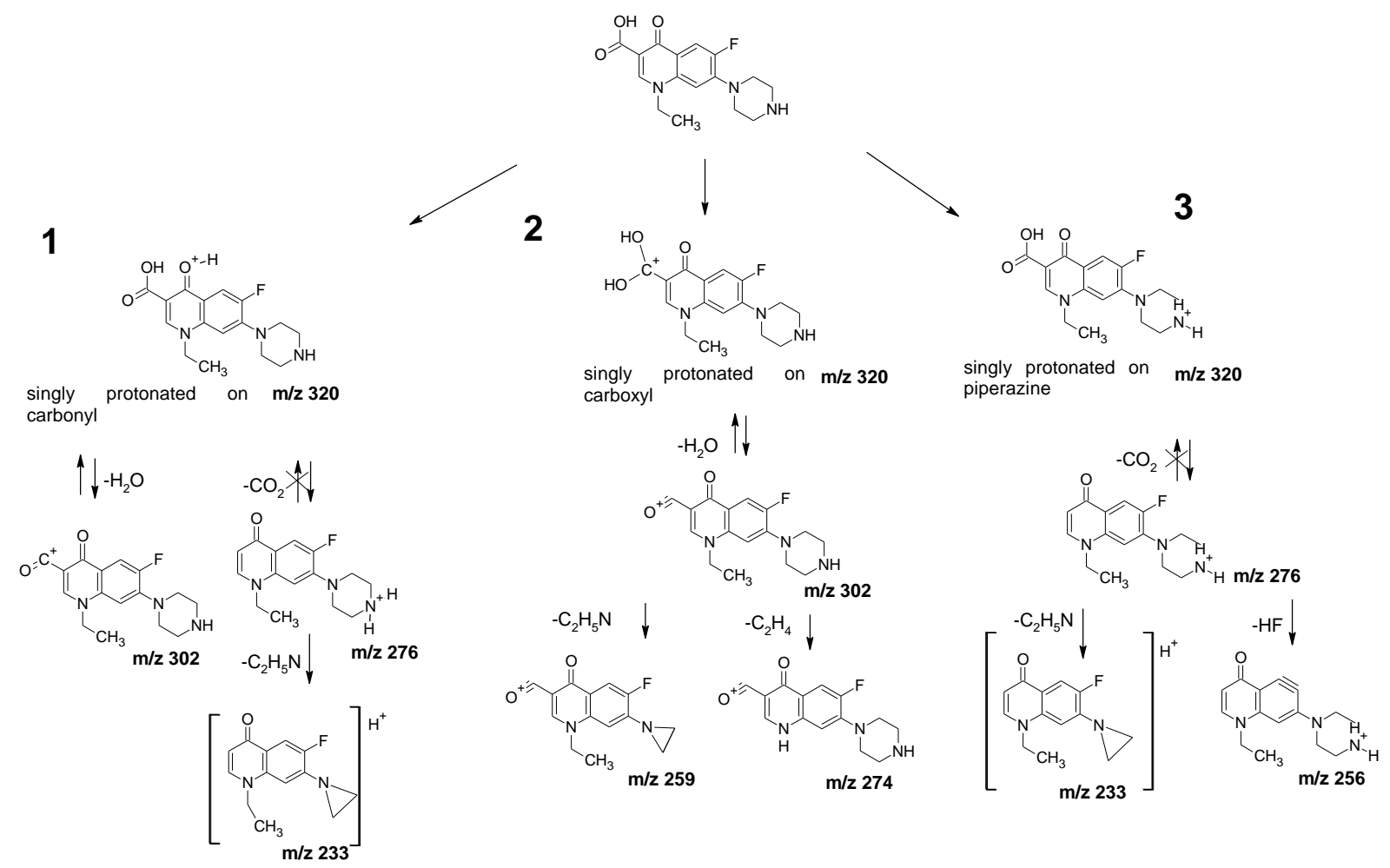

Scheme 2. Proposed fragmentation pathways for norfloxacin including all three components observed in this study

The peaks in the ion mobilogram for norfloxacin reported herein are consistent with a more complex mixture of more than two components, in contrast to what has been previously reported and a fragmentation pathway summary is presented in Scheme 2. It is especially interesting that component 1 is consistent with a loss of both $\mathrm{CO}_{2}$ and $\mathrm{H}_{2} \mathrm{O}$, in contrast to what has previously been reported, where separate fragmentation pathways explain these individual losses.

In Scheme 3 we propose mechanisms for the losses of both $\mathrm{CO}_{2}$ and $\mathrm{H}_{2} \mathrm{O}$ from the norfloxacin ion protonated on the carbonyl group, component 1 . It is interesting to note the degree of delocalisation possible for component 1, which appears to have a larger number of resonance structures than component 2 and component 3. 


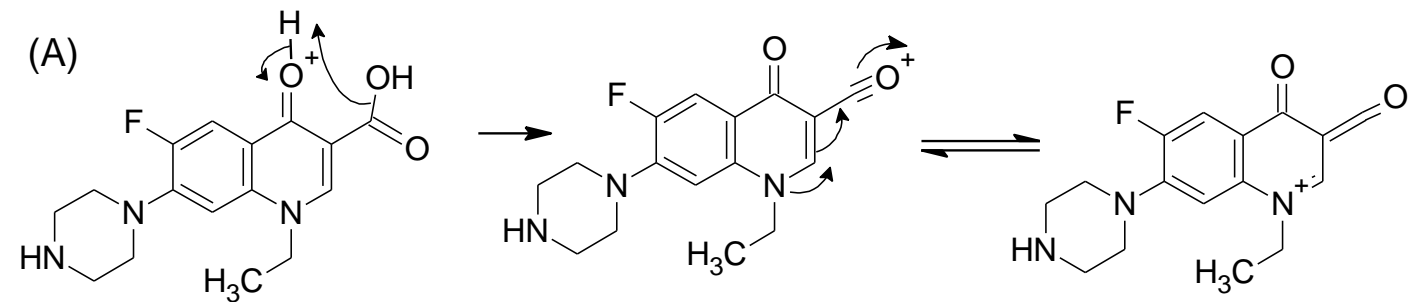<smiles>CCN1C=C(C(=O)O)C(=O)C2C(C)=C(N3CCNCC3)C(F)=CC21</smiles>



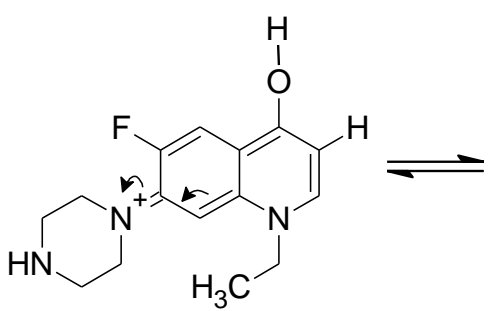<smiles>CCn1ccc2c(O)cc(F)cc2[c+]1C1CCNCCN1</smiles><smiles>CC[n+]1ccc(O)c2cc(F)c(N3CCNCC3)cc21</smiles>

Scheme 3. Proposed fragmentation pathways for norfloxacin including all three components observed in this study

The use of a high efficiency UPLC C18 separation increases confidence that we are not simply observing an impurity, as positional isomers might be expected to be separated in the liquid chromatography dimension. It is also reported that the common synthetic impurities of norfloxacin do not include an isomer with the same $\mathrm{m} / \mathrm{z}$ value. ${ }^{[23]}$

\section{Molecular modelling using Density Functional Theory}

To further understand the likely protonation sites in norfloxacin (Scheme 4) DFT calculations were undertaken using an initial geometry based on a recently obtained crystal structure ${ }^{[15]}$ and are collected in Table 1. The geometry was optimised at the B3LYP/6-311++G(d,p) level. It is noticeable that there is a hydrogen bond between the carboxyl group and carbonyl group which is consistent with several condensed phase studies including for the solvated neutral and zwitterion species using molecular modelling, ${ }^{[4}$ capillary electrophoresis, ${ }^{[24]}$ spectrophotometric methods ${ }^{[25]}$ potentiometric methods ${ }^{[26]}$ and infra-red spectroscopy. ${ }^{[27]}$ 




Scheme 4. Structure and atom numbering scheme for norfloxacin and dashed line highlighting proposed hydrogen bond.

Table 1. Norfloxacin structures with calculated minimum energies and proton affinities

\begin{tabular}{|c|c|c|c|c|c|c|}
\hline $\begin{array}{c}\text { Protonation } \\
\text { site }\end{array}$ & $\begin{array}{c}\Delta E(\mathbf{k J} \\
\left.\mathrm{mol}^{-1}\right)^{(\mathbf{a})}\end{array}$ & $\underset{\left.\mathrm{mol}^{-1}\right)^{(\mathbf{b})}}{\Delta E(\mathbf{k J}}$ & Structure & $\begin{array}{c}\text { PA } \\
{ }^{\mathbf{t}} \mathbf{C C S} \\
\left(\AA^{2}\right)\end{array}$ & $\begin{array}{l}{ }^{e} \mathbf{C C S} \\
\left(\AA^{2}\right)\end{array}$ & $\begin{array}{c}\text { Dipole } \\
\text { momen } \\
\text { (D) }\end{array}$ \\
\hline $\mathrm{n} / \mathrm{a}$ & 0.0 & 0.0 & & 111.14 & n.d. & 11.02 \\
\hline $\begin{array}{c}\text { O18 } \\
\text { (component }\end{array}$ & $\begin{array}{c}-948.4 \\
(1)\end{array}$ & n.d. & & 111.60 & 100.58 & 4.37 \\
\hline $\begin{array}{c}\mathrm{O} 23 \\
\text { (component } \\
2 \text { ) }\end{array}$ & $\begin{array}{c}-871.0 \\
(4)\end{array}$ & $\begin{array}{c}-980.4 \\
(1)\end{array}$ & & 112.12 & 107.34 & 13.89 \\
\hline $\begin{array}{c}\mathrm{N} 4 \\
\text { (component }\end{array}$ & $\begin{array}{c}-944.4 \\
(2)\end{array}$ & $\begin{array}{c}-905.8 \\
(2)\end{array}$ & & 111.85 & 118.38 & 30.67 \\
\hline N1 & $\begin{array}{c}-929.2 \\
\text { (3) }\end{array}$ & $\begin{array}{c}-903.4 \\
(3)\end{array}$ & & 112.75 & n.d. & 18.42 \\
\hline N14 & $\begin{array}{c}-799.8 \\
(5)\end{array}$ & $\begin{array}{c}-772.3 \\
(4)\end{array}$ & & 112.00 & n.d & 8.82 \\
\hline
\end{tabular}


a Calculated in Gaussian 09 as described herein

b Adapted from Neta et al. ${ }^{(2010)[5]}$

ParentheseseParentheses describe the ranking in order of likely protonation sites

All of the initial protonation sites were considered in this study, ignoring any 'educated' prejudice, and the proton was constrained to the $\mathrm{O} 23$ protonation site such that proton migration did not occur, as we considered this unlikely in the millisecond timescale of the IMS-MS experiment. The proton affinities in Table 1 contrast with those found by Neta et al ${ }^{[5]}$ especially for protonation at $\mathrm{O} 23$ which they determined as the most favoured protonation site. Their calculations did not allow for possible protonation on the $\mathrm{O} 18$ position. In this study the proton affinity for 018 , which is reported here for the first time, is relatively favourable, and energetically more favourable than protonation at N4 which has important ramifications for understanding the ion mobility separation and subsequent product ion mass spectra.

\section{Molecular modelling compared to IMS peak heights}

The height of the peaks in the ion mobilogram (Figure 6) shows that component 3 (MS/MS spectrum is consistent with protonation at N4) is more abundant than component 2 (MS/MS spectrum is consistent with protonation at $\mathrm{O} 23$ ) in contrast to the thermodynamic data above suggesting component 2 should be more abundant due to the favourable proton affinity. This appears to indicate that it is not only the thermodynamics that determine the abundance of certain protomers, and that kinetics or steric effects may also be important.

\section{Molecular modelling compared to IMS drift times}

The CCS is experimentally determined from the drift time through the IMS cell. However, all the factors which contribute to ion mobility drift time are not clear, and in special cases (where electrostatic forces play a major role) traditional models of ion mobility may not be applicable. For example, whilst the dipole moment is not explicitly considered in classical ion-neutral collision theory based ion mobility, it is considered to be important in FAIMS ion mobility, and was considered to be an important factor in a six parameter regression model to predict ion mobility constants in a diverse set of 159 compounds. ${ }^{[28]}$ The physical reasons for the dipole moment being important in ion mobility may be related to:

1. the polarisation interaction between an ion and neutral buffer gas and/or contaminant species in the IMS cell. ${ }^{[27]}$

2. interaction of the molecular dipole moment with the electric field of the ion mobility cell and any net alignment with the field which could reduce the effective CCS. ${ }^{[28]}$

Indeed, Neta et al. ${ }^{[7]}$ postulated three different structures with the same mass due to the strong hydrogen bond present potentially leading to a different structures and different mobilities. The calculated dipole moment herein (obtained from the Gaussian output file) varies from $~ 4$ to $\sim 30 \mathrm{D}$ when protonated at different sites, the theoretical calculations predicting a dipole moment for the ion protonated on the amine nearly ten times larger than that for the ion protonated on the carboxyl group, which may explain the unexpected magnitude of the peak separation observed between components 2 and 3 .

Theoretical CCS values were initially calculated using the projection approximation (PA) algorithm in Driftscope software ${ }^{[10]}$ and are shown in Table 3. (Some caution must be taken with the use of MOBCAL for unusual atom types, since the original source code does not include sufficient data for molecules and ions containing some elements (including fluorine), although the code can be modified to suit), whilst Driftscope includes fluorine by default. 
Previous studies on $\mathrm{N}$-protonated aniline and porphyrins ${ }^{[31]}$ have highlighted that significant differences between theoretically determined CCS ( $\left.{ }^{\mathrm{t}} \mathrm{CCS}\right)$ values and experimental determined CCS ( ${ }^{\mathrm{e} C C S}$ ) values may indicate a difference in charge distribution; ions with more localised charges may form longer-lived gas-phase interactions with the mobility buffer gas than delocalised charges. Currently these interactions do not appear to be modelled well using the main theoretical algorithms including projection approximation (PA), exact hard sphere scattering (EHSS) and trajectory method (TM), leading to poor agreement between theoretical and experimental CCS values.

In general the large difference between the ${ }^{t} \mathrm{CCS}$ and ${ }^{\mathrm{e}} \mathrm{CCS}$ indicates one or more factors other than purely the physical CCS is playing a critical role in the separation of these ions. For example the ${ }^{t} \mathrm{CCS}$ for norfloxacin protonated at the N4 position $\left(111.85 \AA^{2}\right)$ is slightly smaller than when protonated at the 023 position $\left(112.12 \AA^{2}\right)$, a difference in CCS between two theoretical CCSs $\left(\Delta^{\mathrm{t}} \mathrm{CCS}\right)$ of $0.27 \AA^{2}$, whereas these species are observed to be well separated (shown in Figures 1 and 9) which is surprising considering the small $\Delta^{t} \mathrm{CCS}$. Indeed the ${ }^{\mathrm{e}} \mathrm{CCS}$, calibrated using poly(DL-alanine), for component 2 is $118.38 \AA^{2} \pm 0.13$ and for component 1 a value of $107.3 \AA^{2} \pm 0.24$, a difference in experimental CCS $\left(\Delta^{\mathrm{e}} \mathrm{CCS}\right)$ of $11.08 \AA^{2}$.

There is a very good correlation between the rank order of the molecular dipole (D) and the drift time, with the ions with larger dipoles also found to have a longer drift time, resulting in calculation of a larger ${ }^{\mathrm{e}} \mathrm{CCS}$. It is remains to be seen whether this example can be extrapolated to other compounds which exhibit a range of dipoles and a relatively small difference in ${ }^{\mathrm{t}} \mathrm{CCS}$, in effect whether dipole moment can be an important predictor for ${ }^{\mathrm{e}} \mathrm{CCS}$ using TWIMS. Drift times were correlated with the dipole moment in the study of corrole isomers ${ }^{[32]}$ using $\mathrm{CO} 2$ as the drift gas, albeit this study uses the less polarizable $\mathrm{N}_{2}$ drift gas.

There is also a general trend of larger ${ }^{\mathrm{t}} \mathrm{CCS}$ than ${ }^{\mathrm{e}} \mathrm{CCS}$ using PA for two of the three detected ions, which is surprising as any attractive electrostatic interactions present in the IMS cell, such as an induced dipole leading to a non-Newtonian collision between analyte and buffer gas might be expected to generate a larger effective collision cross section, leading to a larger ${ }^{\mathrm{e}} \mathrm{CCS}$, and an underestimation of ${ }^{\mathrm{t}} \mathrm{CCS}$. PA is also known to overestimate ${ }^{\mathrm{t}} \mathrm{CCS}$ by up to $20 \%$ for concave structure. ${ }^{[33]}$

\section{CONCLUSIONS}

Mutiple protonation sites are not typically explicitly considered in interpretation of mass spectrometry and ion mobility data, indeed ions from different protonation sites may well be conflated to obscure relationships between structure and fragmentation pathways. It may be difficult to predict the site of protonation purely based on solution-phase $\mathrm{pKa}$ or gas-phase basicity thermodynamics as kinetic effects also play a part in the process. The calculation of gas-phase basicities using DFT for all potential protonation sites in norfloxacin, without exclusion by 'educated' bias, reveals an unexpected protonation site which is thermodynamically favourable. The additional information from DFT and IMS-MS/MS adds confidence to assignment of the protonation site and thus fragmentation pathway.

In the case of norfloxacin reported herein, ion mobility mass spectrometry data is treated like liquid chromatography mass spectrometry data to deconvolute the data and reveal the presence of 3 components, albeit 2 components ( 1 and 2) are effectively eluted under 1 ion 
mobility peak under the initial experimental conditions. An improvement in separation was achieved by changing the ion mobility conditions, but this might not always be feasible so careful processing, taking into account the presence and absence of peaks in the mass spectra and their intensity, may reveal further information on mixtures analysed using ion mobility mass spectrometry.

The deconvolution of ion mobility mass spectrometry data may be especially useful where mass spectrometry and ion mobility spectrometry alone may not be able to distinguish between different components ${ }^{[34]}$ and the extra dimension added by DFT should help with assignment of ion mobility and mass spectrometry data.

\section{REFERENCES}

[1] J. J. Irwin, T. Sterling, M. M. Mysinger, E. S. Bolstad, R. G. Coleman. ZINC: A Free Tool to Discover Chemistry for Biology. J Chem Inf Model. 2012, 52, 1757.

[2] http://accelrys.com/products/databases/bioactivity/mddr.html

[3] A. Kaufmann, P.Butcher, K. Maden, M. Widmer, K. Giles, and D. Uría. Are liquid chromatography/electrospray tandem quadrupole fragmentation ratios unequivocal confirmation criteria? Rapid Comms., 2009, 23, 985.

[4] G. P. Vitorino, G. D. Barrera. M. R. Mazzieri. R.C. Binning Jr., D. E. Bacelo. A DFT study of hydration in neutral and zwitterionic norfloxacin. Chem. Phys. Lett. 2006, 432, 538.

[5] P. Kebarle , M. Peschke On the mechanisms by which the charged droplets produced by electrospray lead to gas phase ions. Anal. Chim. Acta. 2000, 406, 11.

[6] J. Wang, A. Aubry, M. S. Bolgar, H. Gu, T. V. Olah, M. Arnold, M. Jemal. Effect of mobile phase $\mathrm{pH}$, aqueous-organic ratio, and buffer concentration on electrospray ionization tandem mass spectrometric fragmentation patterns: implications in liquid chromatography/tandem mass spectrometric bioanalysis. Rapid Comms. 2010, 24, 3221.

[7] P. Neta, B. Godugu, Y. Liang, Y. Simón-Manso, X. Yang, S. E. Stein. Electrospray tandem quadrupole fragmentation of quinolone drugs and related ions. On the reversibility of water loss from protonated molecules. Rapid Comms. 2010, 24, 3271.

[8] R. Tuytten, F. Lemière, W. Van Dongen, E. L. Esmans, E. Witters, W. Herrebout, B. Van Der Veken, E. Dudley, R. P. Newton. Intriguing Mass Spectrometric Behavior of Guanosine Under Low Energy Collision-Induced Dissociation: H2O Adduct Formation and Gas-Phase Reactions in the Collision Cell. J. Am. Chem. Soc. 2005, 16, 1291.

[9] S. Beuck, T. Schwabe, S. Grimme, N. Schlörer, M. Kamber, W. Schänzer, M. Thevis. Unusual mass spectrometric dissociation pathway of protonated isoquinoline-3-carboxamides due to multiple reversible water adduct formation in the gas phase. J. Am. Chem. Soc, 2009, 20, 2034. 
[10] J. P. Williams, J. A. Lough, I. Campuzano, K. Richardson, P. J. Sadler. Use of ion mobility mass spectrometry and a collision cross-section algorithm to study an organometallic ruthenium anticancer complex and its adducts with a DNA oligonucleotide. Rapid Comms. 2009, 23, 3563.

[11] S. C. Henderson, S. J. Valentine, A. E. Counterman, D. E. Clemmer. ESI/Ion Trap/Ion Mobility/Time-of-Flight Mass Spectrometry for Rapid and Sensitive Analysis of Biomolecular Mixtures. Anal. Chem., 1999. 71, 291.

[12] M. J. Frisch, G. W. Trucks, H. B. Schlegel, G. E. Scuseria, M. A. Robb, J. R. Cheeseman, G. Scalmani, V. Barone, B. Mennucci, G. A. Petersson, H. Nakatsuji, M. Caricato, X. Li, H. P. Hratchian, A. F. Izmaylov, J. Bloino, G. Zheng, J. L. Sonnenberg, M. Hada, M. Ehara, K. Toyota, R. Fukuda, J. Hasegawa, M. Ishida, T. Nakajima, Y. Honda, O. Kitao, H. Nakai, T. Vreven, J. A. Montgomery, Jr., J. E. Peralta, F. Ogliaro, M. Bearpark, J. J. Heyd, E. Brothers, K. N. Kudin, V. N. Staroverov, R. Kobayashi, J. Normand, K. Raghavachari, A. Rendell, J. C. Burant, S. S. Iyengar, J. Tomasi, M. Cossi, N. Rega, J. M. Millam, M. Klene, J. E. Knox, J. B. Cross, V. Bakken, C. Adamo, J. Jaramillo, R. Gomperts, R. E. Stratmann, O. Yazyev, A. J. Austin, R. Cammi, C. Pomelli, J. W. Ochterski, R. L. Martin, K. Morokuma, V. G. Zakrzewski, G. A. Voth, P. Salvador, J. J. Dannenberg, S. Dapprich, A. D. Daniels, Ö. Farkas, J. B. Foresman, J. V. Ortiz, J. Cioslowski, D. J. Fox, Gaussian, Inc., Wallingford CT, 2009.

[13] A. D. Becke, Density-functional thermochemistry III. The role of exact exchange. $J$. Chem.Phys., 1993, 98, 5648.

[14] C. Lee, W. Yang, R. G. Parr, Development of the Colle-Salvetti correlation-energy formula into a functional of the electron-density, Phys. Rev. B, 1988, 37, 785.

[15] J. J. Holstein, C. B. Hübschle, B. Dittrich. Electrostatic properties of nine fluoroquinolone antibiotics derived directly from their crystal structure refinements. CrystEngComm., 2012, 14, 2520.

[16] J. R. Joyce, D. S. Richards. Kinetic Control of Protonation in Electrospray Ionization. $J$. Am. Soc. Mass Spectrom., 2011, 22, 360.

[17] D. J. Burinsky, J. D. Williams, A. D. Thornquest, S. L. Sides, Mass spectral fragmentation reactions of a therapeutic 4-azasteroid and related compounds, J. Am. Soc. Mass Spectrom., 2001, 12, 385.

[18] A. Alex, S. Harvey, T. Parsons, F. S. Pullen, P. Wright, J. Riley. Can density functional theory (DFT) be used as an aid to a deeper understanding of tandem mass spectrometric fragmentation pathways?, Rapid Comms, 2009, 23, 2619.

[19] Y. Chai, H. Sun, Y. Pan, C. Sun. N-Centered Odd-Electron Ions Formation from Collision-Induced Dissociation of Electrospray Ionization Generated Even-Electron Ions: Single Electron Transfer via Ion/Neutral Complex in the Fragmentation of Protonated N,N'-Dibenzylpiperazines and Protonated N-Benzylpiperazines, J. Am. Soc. Mass Spectrom., 2011, 22, 1526. 
[20] M. Joseph Youssefi, A. F. Boschung, A. F. Thomas, F. W. McLafferty. Conformation dependence in the chemical ionization mass spectra of 3-pinanones, Rapid Comms, 1994, 8, 313.

[21] S. Chervenkov, P. Q. Wang, J. E. Braun, H. J. Neusser. Fragmentation and conformation study of ephedrine by low- and high-resolution mass selective UV spectroscopy. J. Chem. Phys., 2004. 121, 7169.

[22] J. Deutsch, A. Mandelbaum. Studies in mass spectrometry. Part XIV. The effect of conformation on the electron impact-induced fragmentation of adducts of p-benzoquinone and 1,1'-bicycloalkenyls, J. Chem. Soc., B. 1971, 886.

[23] N Rao, R Nagaraju, V Nagaraju. Separation and Determination of Synthetic Impurities of Norfloxacin by Reversed-phase High Performance Liquid Chromatography. J. Pharm. Biomed. Anal., 2004, 34, 1049.

[24] C-E Lin , Y-J Deng, W-S Liao, S-W Sun, W-Y Lin, C-C Chen. Electrophoretic behavior and $\mathrm{pKa}$ determination of quinolones with a piperazinyl substituent by capillary zone electrophoresis. J. Chromatogr. 2004, 1051, 283.

[25] H-R Park, K-Y Chung, H-C Lee, J-K Lee, K-M Bark. Ionization and Divalent Cation Complexation of Quinolone Antibiotics in Aqueous Solution. Bull. Korean Chem. Soc., 2000, 21,849 .

[26] J. Barbosa, R. Bergés, I. Toro, V. Sanz-Nebot. Protonation equilibria of quinolone antibacterials in acetonitrile-water mobile phases used in LC. Talanta 1997, 1271.

[27] M. Jelikic̀, D. Veselinovic̀, P. Djurdjevic̀. Acid-base equilibria in substituted 4-quinolone carboxylic acid solutions. Talanta 1992, 39, 665.

[28] H. Liu, X. Yao, M. Liu, Z. Hu, B. Fan. Prediction of gas-phase reduced ion mobility constants $(\mathrm{K}(0))$ based on the multiple linear regression and projection pursuit regression. Talanta 2007, 71, 258.

[29] L. W. Beegle, I. Kanik, L. Matz, H. H. Hill. Effects of drift-gas polarizability on glycine peptides in ion mobility spectrometry. Int. J. Mass spectrum. 2002, 216, 257.

[30] B. T. Ruotolo, J. L. P. Benesch, A. M. Sandercock, S.-J. Hyung, C. V. Robinson. Ion mobility-mass spectrometry analysis of large protein complexes. Nat. Protocols, 2008, 3 1139.

[31] P. M. Lalli, B. A. Iglesias, H. E. Toma, G. F. de Sa, R. J. Daroda, J. C. Silva Filho. Protomers: formation, separation and characterization via travelling wave ion mobility mass spectrometry. J. Mass Spectrom. 2012, 47, 712.

[32] M. Fasciotti, A. F. Gomes, F. C. Gozzo, B. A. Iglesias, G. F. de Sá, R. J. Daroda, M. Toganoh, H. Furuta, K. Araki, M. N. Eberlin. Corrole isomers: intrinsic gas-phase shapes via traveling wave ion mobility mass spectrometry and dissociation chemistries via tandem mass spectrometry. Org. Biomol. Chem., 2012, 10, 8396. 
[33] A. A. Shvartsburg, M. F. Jarrold. An exact hard-spheres scattering model for the mobilities of polyatomic ions. Chem. Phys. Lett., 1996, 261, 86.

[34] L. Sunyoung, L. Zhiyu, S. J. Valentine, S. M. Zucker, N. Webber, J. P. Reilly, D. E. Clemmer. Extracted fragment ion mobility distributions: A new method for complex mixture analysis, Int. J. Mass Spectrom, 2012, 309, 154. 